\title{
SiM
}

\section{Building a Teaching Technology Toolbox for Rangeland Ecology}

\author{
By Beth A. Newingham, Amy C. Ganguli, and Barron J. Orr
}

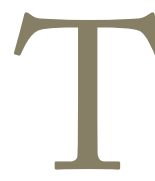

he world is becoming more connected and integrated with technology by the minute, and the academic world is no exception. Students are of the Digital Age, and faculty struggle to keep up. Despite the technological literacy of students, schools and universities still provide the scientific background and applicable tools for rangeland ecology and management careers. Thus, instructors can use technology and online resources as learning tools to develop students' understanding of scientific fundamentals, core competences, and practical skills necessary for the workplace. Here, we discuss the reasons to use technology and online resources, provide examples applicable to rangeland ecology and management, and discuss considerations when employing technology in teaching.

\section{Why Use Technology?}

Technology should be viewed as an additional tool for an instructor's repertoire rather than a replacement of traditional teaching methods. ${ }^{1}$ In fact, adding technology can enhance a student's learning experience and supplement concepts presented in more-traditional ways. With careful planning, an instructor can assemble appropriate technology tools to achieve the following learning objectives:

\section{Facilitate Communication Skills}

Just when we think we have mastered e-mail, students are no longer checking e-mail and are now communicating more via texting, Facebook, and Twitter. Although these technologies are used in ways that require adjustments on the part of instructors, when used correctly, they have the potential to increase quality of communication. Students are constantly connected and communicating; instead of thinking of technology as distancing us from our students, it is an opportunity to further communicate with our students. Moreover, these technologies encourage self-direction, content contribution, and the collaborative construction of knowledge, which are qualities we strive to encourage in our students. ${ }^{2}$ Using technology also allows us to communicate with students outside the classroom, which facilitates extra interaction and learning. In fact, remote communication may work better for some students who would otherwise be shy to approach faculty or interact with other students in class.

\section{Foster Active and Problem-Based Learning}

Traditional teaching methods, such as lecturing, are passive learning methods that present students with information but do not develop problem-solving skills. ${ }^{3}$ Technology can also promote active and collaborative, problem-based learning by facilitating, rather than directing, problem solving via interactive software and tools. ${ }^{4}$ Online communication and projects can also increase cooperative, collaborative, and peer learning. ${ }^{5}$ For example, students can work on group projects to develop cooperative and collaborative skills while teaching their peers how to use the technology. Having students evaluate case studies or conduct simulated experiments online will help develop problem-based skills.

\section{Increase Information Access and Networking}

An advantage to using technology and online resources in teaching is that it increases the instructor and students' access to information and expertise through the plethora of information waiting at our fingertips via the Internet. Having students find information online and evaluate its credibility teaches research and critical thinking skills. Using these online resources also allows instructors to take students virtually outside the classroom. Instructors can expose students online to other ecosystems and associated scientific concepts via videos and pictures of places they may not be able to see otherwise. Online resources also allow students to gain access to Webinars and other forms of communication with professionals and experts from around the world. With today's reality of time, money, and travel constraints, using online resources offers an opportunity to expand students' ability to learn about the outside world.

\section{Teach Technological Skills for the Workplace}

As producers, managers, instructors, and researchers, we know the demands for technological skills at the workplace are always increasing. This means that by using technology and online resources to address a variety of learning objectives, we can simultaneously prepare students with some of 
the technological skill sets increasingly necessary for their careers. This can be in the form of activities that facilitate data collection, inventory, and monitoring. It also includes enhanced writing skills derived from encouraging online communication associated with course work. For example, instructors can encourage students to use Web of Knowledge (Thomson Reuters, New York, NY) to support scientific writing and literature reviews, Doodle (Doodle AG, Zurich, Switzerland) ${ }^{\mathrm{ii}}$ for polls and scheduling, Google Docs (Google, Inc, Mountain View, CA) $)^{\text {iii }}$ for collaborative writing and data organization, and Google Sites (Google, Inc)iv for project coordination. Instructors can integrate many of these programs and techniques together to develop a suite of technological skills for students.

\section{Examples of Relevant Technologies}

There are various software, databases, and online tools available for instructors to construct and conduct courses. Using technology and online resources allows instructors to present lectures electronically, post syllabi and other course materials online, facilitate guest lectures, generate rubrics, and even create online quizzes and textbooks. Although our lists are certainly not exhaustive, examples of course management systems include Blackboard (Blackboard Inc, Washington, DC), ${ }^{v}$ WebCT ("Course Tools," Blackboard Inc; now transitioning to Blackboard), Desire2Learn (D2L Ltd, Baltimore,

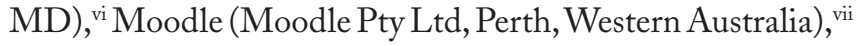
ITunesU (Apple, Cupertino, CA), ${ }^{\text {viii }}$ and for those wanting to do it more themselves, Google Sites. In addition, instructors can use various forms of collaboration tools, including Skype (Skype, Inc, Palo Alto, CA), ${ }^{\text {ix }}$ Google Docs, Google Groups (Google, Inc), ${ }^{\mathrm{x}}$ Dropbox (Dropbox Inc, San Francisco, CA), ${ }^{\mathrm{xi}}$ and Picasa (Google, Inc). ${ }^{\text {xii }}$ With a little research and recommendations from other colleagues, instructors can build their own teaching technology toolbox to fit their needs.

An easy way to incorporate technology into the classroom involves consulting the wide variety of online databases for materials and ideas on teaching (Table 1). Applicable databases for rangeland ecology and management may include species identification/nomenclature Web sites such as the USDA PLANTS database, ${ }^{\text {xiii }}$ Ecological Site Information

\footnotetext{
'Web of Knowledge, http://wokinfo.com.

i" Doodle, http://www.doodle.com.

iii Google Docs, https://docs.google.com; also, Google Docs for Educators, http://www.google.com/educators/p_docs.html.

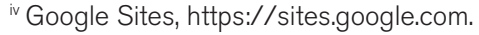

v Blackboard, http://www.blackboard.com.

vi Desire2Learn, http://www.desire2learn.com.

vii Moodle, http://moodle.org.

viii ITunesU, http://www.apple.com/education/itunes-u/.

ix Skype, http://www.skype.com.

${ }^{\times}$Google Groups, http://groups, google.com.

${ }^{x i}$ Dropbox, https://www.dropbox.com.

xii Picasa, http://picasa.google.com.

xiii NRCS, http://plants.usda.gov.
}

System (ESIS, NRCS), ${ }^{\text {xiv }}$ Fire Effects Information System (FEIS, USDA Forest Service), ${ }^{\mathrm{xv}}$ and the Fire Research and Management Exchange System (FRAMES, US Center for Biological Informatics, Denver, CO, among other groups participating). ${ }^{\text {viv }}$ Instructors can pull material from these Web sites, as well as structure student research assignments around gathering information from these resources.

Rangeland ecology and management is interdisciplinary by nature, meaning instructors will need to tap into resources from the appropriate disciplines, including soil science, ecology, climate science, earth science, and conservation biology, to name a few. This requires instructors to adapt existing materials from closely related disciplines to meet their teaching goals or create new material themselves. To illustrate this, we provide three examples of ways rangeland ecology and management instructors can increase communication, problemsolving, and geospatial skills for students via communicationdriven, problem-based, and inquiry-based learning.

\section{Communication-Driven Learning via Blogs}

Blogs are online Web logs that form a chronologically organized and searchable collection of content. Contemporary blogs support text-based material, links, photos, and audio or video clips, and they have search options to facilitate information finding. In teaching, blogs are increasingly being used to facilitate student participation in course-related discussion, to encourage students to synthesize their thoughts in the form of online journals or portfolios, to encourage analysis and critical thought by posting questions and responses to others' blog posts, and to develop written communication skills. The benefits of incorporating blogs in classes include 1) free blog-hosting sites, 2) an objective method of gauging participation, 3) guest bloggers who demonstrate expertise, and 4) a comfortable environment for students to share their opinion. There are many avenues for instructors to build and design blogs; some educational blog examples can be found at Edublogs (Austin, TX), ${ }^{\text {xvi }}$ as well as surfing the Web for blogs that are related to the topics or disciplines of interest.

The primary types of blogs used in teaching are focused on instructors, the community, and learners. ${ }^{6}$ In blogs that are instructor-focused, the instructor retains ownership and provides most of the content. Students are encouraged to post questions, and the instructor responds and may post supplementary material to reinforce topics covered in lecture. To increase participation, instructors may require students to post as a portion of their participation grade.

Community-focused blogs add the dimension of involving guest bloggers that are experts or practitioners in the field of study. ${ }^{6}$ Certain subjects discussed in class may benefit from additional subject-matter expertise. Thus, community-fo-

\footnotetext{
xiv ESIS, http://esis.sc.egov.usda.gov.

${ }^{x v}$ FEIS, http://www.fs.fed.us/database/feis/.

xvi FRAMES, http://www.frames.gov.

xvii Edublogs, http://edublogs.org.
} 
Table 1. Examples of information databases for students and instructors in rangeland ecology and management and related disciplines

\section{Information Databases}

Australian Collaborative Rangelands Information System (ACRIS)

\section{CalPhotos}

Ecological Site Information System (ESIS)

\section{Encyclopedia of Earth (EoE)}

\section{ESA EcoEd Digital Library}

Fire Effects Information System (FEIS)

Fire Research and Management Exchange System (FRAMES)

Forage Information System (FIS)

Global Rangelands Knowledge System

National Climatic Data Center (NCDC)

NRCS Soils Web site

Range Science Information System (RSIS)

Rangelands West

Web of Knowledge

UC IPM Online, Statewide Integrated Pest Management Program

USDA Field Office Technical Guides (FOTG)

\section{USDA PLANTS Database}

\section{URL}

http://www.environment.gov.au/land/rangelands/acris/

http://calphotos.berkeley.edu

http://esis.sc.egov.usda.gov/ESIS/

http://www.eoearth.org

http://ecoed.esa.org

http://www.fs.fed.us/database/feis/

http://www.frames.gov

http://forages.oregonstate.edu

http://globalrangelands.org

http://www.ncdc.noaa.gov

http://soils.usda.gov

http://arc.lib.montana.edu/range-science/

http://rangelandswest.org

http://wokinfo.com

http://www.ipm.ucdavis.edu/PMG/

http://www.nrcs.usda.gov/wps/portal/nrcs/main/national/ technical/fotg/

http://plants.usda.gov cused blogs are used to provide guest expertise and to provide opportunities for students to interact with guest lecturers to ask additional questions. Instructors or students may be in charge of recruiting a guest blogger giving students ownership of the process and requiring them to develop their communication skills.

In support of learner-centered teaching, learner-focused blogs place higher levels of expectation on students to actively participate. In ideal situations, students create and maintain their own blogs, and fellow classmates and the instructor provide feedback on blog posts in the form of questions, comments, or critiques. At North Dakota State University (Fargo, ND), instructors of the graduate level "College Science Teaching" course require each student to develop and maintain a blog that students can make public or keep private, so that only members of the class can view. Students are 
prompted to blog about certain topics and encouraged to offer posts on teaching and learning that are more open-ended (i.e., students can select topics to write about, often based on reflections from lecture materials or class discussions). Blog posts by each student are aggregated using Google Reader (Google, Inc) to facilitate reading and commenting on each others' posts.

\section{Problem-Based Learning via Virtual Laboratories}

Although field trips and experiments are valuable exercises for students, these activities can be constrained by time, money, equipment, weather, and safety. Virtual laboratories can provide an inquiry-based opportunity for students to learn concepts that they might not otherwise experience. In particular, well-designed "virtual labs" that engage students in simulated experiments increase their understanding of the scientific method, sampling, statistics, and ecological concepts.

Virtual laboratory programs that focus on ecology can be adapted to fit rangeland topics. SimBiotic Software (Ithaca, $\mathrm{NY})^{\text {xviii }}$ produces cross-platform, virtual learning products for both the kindergarten through 12 th grade $(\mathrm{K}-12)$ and college levels. The software is downloadable to classroom or student computers, and each laboratory comes with a workbook that allows students to complete the exercises independently. The laboratory instructions are offered in either portable document (PDF) or Microsoft Word format, so that the instructor may adapt the laboratory to their specific needs by removing or adding content. These virtual laboratories can be used during a class or laboratory or be assigned as homework for either oncampus or online students.

SimBio Virtual Labs are built around computer models of biological systems, where students can alter inputs and observe and record outputs from different scenarios. Students are provided with a control panel to regulate inputs and observe graphically how their inputs may affect certain variables. For example, in Figure 1A students can select butterfly habitat configurations, fire frequency, and other attributes in the lower right panel. The left panel shows students what this habitat configuration looks like and can observe populations changing over time through visual displays of the patches and butterflies. In addition, students can quantitatively observe how butterfly population size is changing via the graph in the top right panel. The program also includes interactive background material on the species being studied (not shown) and a "Test Your Understanding" feature that provide students instant feedback to questions at the end of each exercise (Figure 1B). Instructors can also use an optional set of autograded questions at the end of each laboratory.

Well-designed, virtual laboratories are great tools to teach the scientific method, sampling design, data collection, graphing, statistics, data interpretation, and modeling. Because students are provided background information for each

xviii SimBiotic Software, http://www.simbio.com.

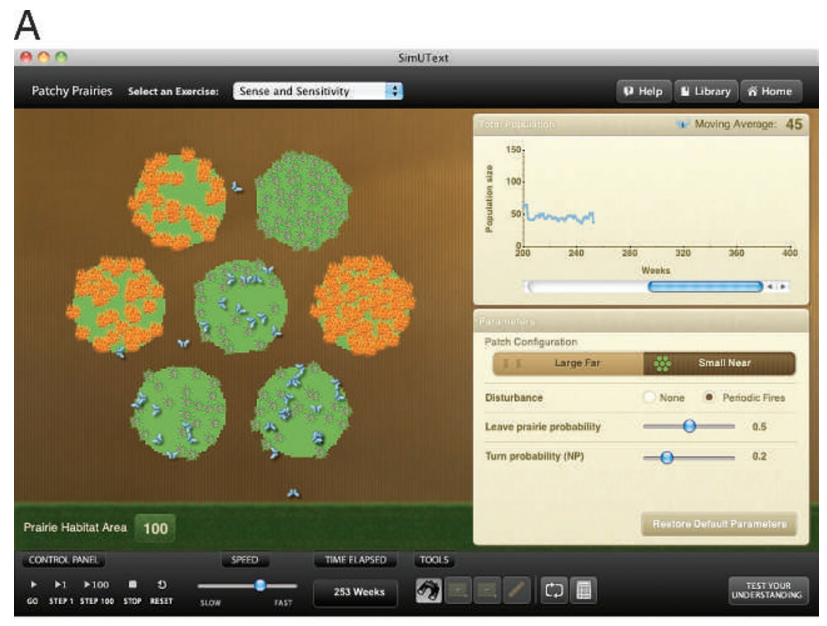

B

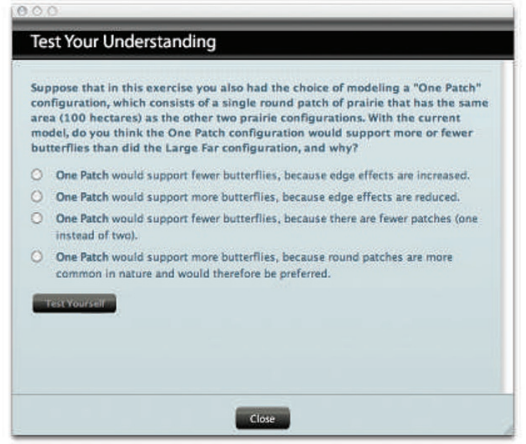

Figure 1. A, Screenshot of the control panel of the "Patchy Prairies" virtual laboratory from SimBio Virtual Labs (http://simbio.com). Students can control input variables and examine outputs via graphs. B, A "Test Your Understanding" dialog is available for students to click on in the control panel to answer questions related to the laboratory.

laboratory, they can make predictions on what might happen in certain scenarios, form testable hypotheses, and create experimental designs to test these hypotheses. In addition, the different scenarios require students to record and graph data, which is mostly done by hand. These handmade graphs are an excellent tool to increase students' understanding of how to represent data and read graphs. By creating comparisons with data outputs, instructors can also include statistical analyses in these laboratories. Combined, all these tasks lead students to develop skills for data interpretation and critical thinking.

The most applicable collection for rangeland ecology and management is the SimBio Virtual Labs Ecobeaker Suite, which explores ecological concepts as well as the data processing mentioned above. For example, students can learn more about population dynamics, nutrient cycling, the intermediate disturbance hypothesis, or habitat restoration through various laboratories. Some laboratories require students to think about management and conservation implications, and others can be modified easily to add these exercises. Examples are provided in Table 2 with a description of each labora- 
Table 2. Examples of Ecobeaker virtual laboratories, including a description, the scientific and management topics covered, and applicable rangeland courses for each laboratory

\begin{tabular}{|c|c|c|c|}
\hline Laboratory & Description & $\begin{array}{l}\text { Scientific concepts/man- } \\
\text { agement }\end{array}$ & $\begin{array}{l}\text { Applicable rangeland } \\
\text { courses }\end{array}$ \\
\hline Isle Royale & $\begin{array}{l}\text { Students explore population } \\
\text { dynamics and species inter- } \\
\text { actions among vegetation, } \\
\text { moose, and gray wolves. }\end{array}$ & $\begin{array}{l}\text { Vegetation dynamics } \\
\text { Predator-prey cycles } \\
\text { Population growth and } \\
\text { dynamics } \\
\text { Carrying capacity } \\
\text { Wildlife habitat management } \\
\text { Climate change and pro- } \\
\text { ductivity }\end{array}$ & $\begin{array}{l}\text { General ecology } \\
\text { Wildlife ecology } \\
\text { Habitat management } \\
\text { Rangeland ecology and } \\
\quad \text { management } \\
\text { Grazing ecology }\end{array}$ \\
\hline Patchy Prairies & $\begin{array}{l}\text { Students design a habitat- } \\
\text { restoration plan for an en- } \\
\text { dangered butterfly species, } \\
\text { which is threatened by fire } \\
\text { suppression, urbanization, } \\
\text { and agriculture. }\end{array}$ & $\begin{array}{l}\text { Landscape ecology-habitat } \\
\text { fragmentation, patch size, } \\
\text { connectivity, edge effects } \\
\text { Habitat restoration using fire } \\
\text { Conservation and endan- } \\
\text { gered species manage- } \\
\text { ment } \\
\text { Sensitivity analysis }\end{array}$ & $\begin{array}{l}\text { Restoration ecology } \\
\text { Landscape ecology } \\
\text { Conservation biology } \\
\text { Habitat management }\end{array}$ \\
\hline Prairie Sampling & $\begin{array}{l}\text { Students strategize about } \\
\text { sampling efforts for four dif- } \\
\text { ferent prairie plant species } \\
\text { with different life histories } \\
\text { and spatial distributions } \\
\text { by altering quadrat size, } \\
\text { number, and shape. }\end{array}$ & $\begin{array}{l}\text { Quadrat sampling } \\
\text { Spatial distributions } \\
\text { Population estimates } \\
\text { Vegetation monitoring }\end{array}$ & $\begin{array}{l}\text { Measurements and monitoring } \\
\text { Restoration ecology } \\
\text { General ecology } \\
\text { Grassland ecology }\end{array}$ \\
\hline
\end{tabular}

tory, the scientific and management concepts addressed, and the potential courses for rangeland ecology and management.

\section{Geospatial Inquiry-Based Learning via Google Earth} Google Earth (Google, Inc) ${ }^{\mathrm{xix}}$ is a virtual globe or a geospatial Web-based interface that accesses satellite, aerial imagery, and other geographic data to create three-dimensional representations of the Earth. Commonly referred to as a geographic browser because of its Web-based interface, there are free versions available for Web and mobile applications; for advanced uses, there are professional and enterprise versions available for purchase. Other geographic browsers exist, most notably the National Aeronautics and Space Administration (NASA, Ames Research Center, Moffett Field, CA) World Wind, ${ }^{x x}$ the ESRI (Redlands, CA) ArcGIS Explorer, ${ }^{x x i}$ and Microsoft Virtual Earth

xix Google Earth, http://earth.google.com.

xx NASA World Wind, http://worldwind.arc.nasa.gov.

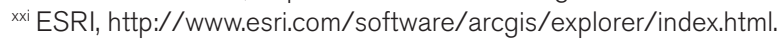

(now, Bing Maps) ${ }^{x x i i}$; our focus on Google Earth is due to its widespread use today by the public and in teaching and learning efforts.

Advantages of using Google Earth in classes include 1) it is free and easy to use, 2) it provides an excellent framework for inquiry-based learning, 3 ) it has a wide user base creating disciplinary-based extensions or applications, 4) it provides instantaneous and locationally relevant access to regularly updated geographic data from a wide variety of public and private sources, and 5) it is increasingly being used as a research tool, which provides the opportunity to link into georeferenced data sets. ${ }^{7}$ Although Google Earth is known primarily as a visualization tool, when used properly by educators, it can be transformed into a powerful, geospatial inquiry tool for a variety of unstructured or structured inquiry-based activities. ${ }^{8}$ To support learning activities and to use Google Earth in the classroom, the

xxii Bing Maps, http://www.microsoft.com/maps/. 
Google Earth for Educators Web site ${ }^{\text {xxiii }}$ provides a wealth of tutorials, information, and examples.

Google Earth uses Keyhole Markup Language (KML) files to store data or $\mathrm{KMZ}$ files, which are zipped $\mathrm{KML}$ files that allow for a wide variety of ancillary, location-specific content to be stored, such as ground-based photos and field observations. Once created, KML or KMZ files can be shared via e-mail or posted on a Web site. Provided users have Google Earth installed on their computers, these files will automatically direct users in a geospatial context to the data, coordinates, and ancillary information stored within the files. These files and the integration of multiple geospatial data sets via "mashups" (easy, fast integration of information or functionality derived from different online sources) ${ }^{8}$ have advanced the utility of Google Earth as an educational tool and have wide appeal for the general public.

Google Earth can be used to support structured or unstructured inquiry in laboratory or homework assignments. For example, students can be given a rangeland-management scenario that would require them to use Google Earth to find the information or data to address their questions and to provide interpretation for the implications of their findings. Google Earth could also be used to augment discussions regarding issues that come up in classroom discussions or lectures. For example, in one of our courses, students posed questions about a case study describing how a wildfire was managed. To support the questions and the need for more information, we examined the fire perimeter in Google Earth and addressed pertinent questions, such as access to terrain, placement of containment lines, and proximity to residential areas.

The rapid development of KML and $\mathrm{KMZ}$ resources by agencies, interest groups, and other educators facilitates the immediate incorporation of these resources in class activities. For example, the interagency InciWeb site ${ }^{\text {xxiv }}$ is an allrisk information system that houses information about fire for interagency and public communication purposes. InciWeb currently provides a KML of all the current fire incidents occurring in the United States. Other KML files have been created that also provide useful geospatial information for rangeland and natural resource management courses; the BLM "Earth Point Township" KML provides Township, Range, and Section delineations for viewing in Google Earth. Another useful KMZ resource is "SoilWeb" (USDA National Cooperative Soil Survey) ${ }^{\mathrm{xxv}}$ which provides Soil Survey Geographic (SSURGO) database polygons of soil-map units that are visible at scales of 1:35,000 or larger.

In Figure 2, we provide a specific example of how to integrate KML and KMZ files for an assignment. We created two KMLs to highlight a particular geographic region

\footnotetext{
xxiii Google Earth for Educators, http://sitescontent.google.com/googleearth-for-educators/.

${ }^{x x i v}$ InciWeb, http://www.inciweb.org.

xxv SoilWeb, http://casoilresource.lawr.ucdavis.edu/drupal/book/export/ html/902/.
}
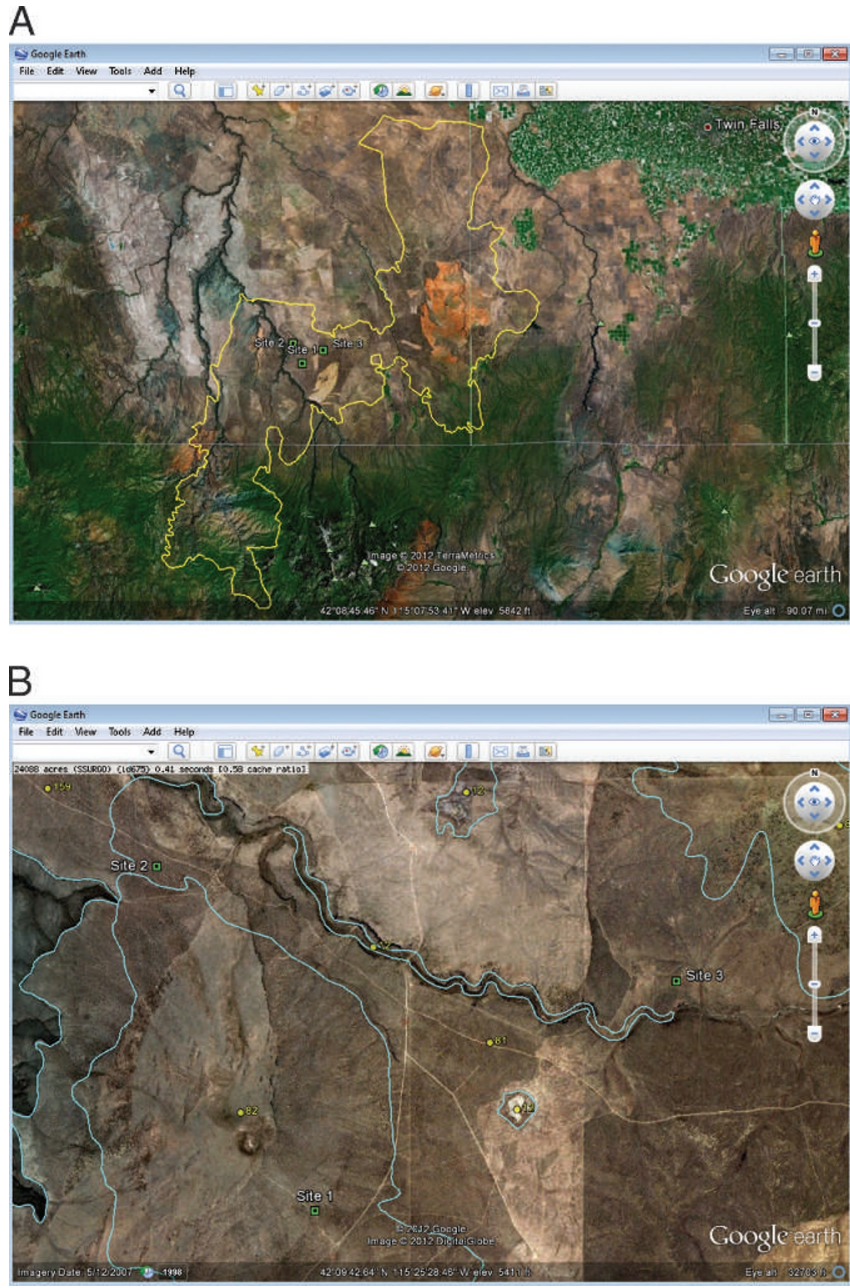

Figure 2. A, Google Earth screen shot of a wildfire perimeter (yellow line) with study-site locations imbedded within the wildfire area (green squares; sites 1-3). Point and polygon features were created as $\mathrm{KML}$ files. B, Google Earth screen shot of the three study locations coupled with the SoilWeb KMZ illustrating the SSURGO soil-mapping units (soilmap units delineated in light blue with the soil map unit labeled in yellow).

(Figure 2A), and students can view the KML files in Google Earth to see a fire perimeter (yellow polygon) and study-site locations (green squares). By coupling these KML layers with the KMZ SoilWeb layer, students can zoom into geographic areas of interest to identify what soils are present (Figure 2B). Students can then be guided through structured questions about soil maps and ecological sites.

\section{Considerations When Using Technology}

It is important to recognize that instructors have different teaching styles, comfort levels, and capabilities. Even though certain teaching styles or tools may be effective for some instructors, they may fail miserably for others. ${ }^{9}$ Thus, it is paramount that instructors evaluate their teaching style and capabilities when considering the use of technology in the classroom and, where necessary, collaborate with others (e.g., enterprising students and colleagues) to help ensure 
Table 3. Examples of teaching and learning communities that provide materials, support, and ideas for instructors in rangeland ecology and management and related disciplines

\begin{tabular}{|c|c|}
\hline Teaching and learning community & URL \\
\hline American Geophysical Union & http://agu.org/education/ \\
\hline Chronicles of Higher Education & http://chronicle.com \\
\hline Climate Literacy \& Energy Awareness Network & http://cleanet.org \\
\hline Climate, Adaptation, Mitigation, E-Learning & http://camelclimatechange.org \\
\hline Ecological Society of America & http://esa.org/education_diversity/educatorResources.php \\
\hline eXtension & http://extension.org \\
\hline National Oceanic and Atmospheric Administration & http://www.education.noaa.gov \\
\hline Range Science Education Council & http://rangelands.org/RSEC/RSEC.htm \\
\hline Society for Conservation Biology & http://conbio.org/Resources/Education/ \\
\hline Soil Science Society of America & http://soils.org/lessons/ \\
\hline The Landscape Toolbox & http://www.landscapetoolbox.org \\
\hline United States Geological Survey & http://education.usgs.gov \\
\hline
\end{tabular}

success. More important, instructors must ensure they are using technology to meet particular learning objectives. ${ }^{5}$

Like any other tool, new technologies come with a learning curve; increased comfort comes with practice and can be enhanced by collaboration with other instructors or students. The steepness of those learning curves often depends on the type of technology. For example, e-mail, course-management systems, blogs, bulletin boards, and social networks represent tools that are relatively easy to learn. Technologies that are more challenging to learn include video clips, Web sites, podcasts, collaboration tools (e.g., Google Groups), simulations, or virtual learning environments. ${ }^{10}$ Many higher-education institutions have information technology or teaching technology support staff to assist with implementation of technologies. Additionally, there are many communities of practices associated with teaching technologies and online resources that are places to find advice for implementation (for examples, see Table 3).

It is essential that technology be employed to support the educational topic and facilitate the achievement of learning objectives. Technology alone will not ensure learning, but it can improve learning if students are engaged and challenged by the task. ${ }^{11}$ Excessive use of technology without clear direction will, potentially, confuse students and serve as a distraction rather than a tool to augment learning. Therefore, it is prudent for instructors to think through their learning objectives when evaluating whether technology will help enhance their teaching.

Increasing class sizes, time constraints, and geographic proximity to suitable field-based activity sites can sometimes limit opportunities for outdoor hands-on activities and field trips. In these situations, virtual laboratory exercises and virtual field trips can be an effective means to emulate and allow the experience of dynamic processes in natural systems. In ideal situations, the virtual learning opportunities are coupled with traditional field-based, experiential learning. ${ }^{12}$ The conceptual understanding obtained in the virtual laboratory supplements the design skills and practical understanding that comes from hands-on experience. ${ }^{13}$

We have all seen the challenges technology presents when things go wrong, including hardware failures, software glitches, and the inability to access the Internet. Because it is impossible to prevent or predict these situations, it is important that instructors are flexible in their approach and plan for potential technology failures. High levels of familiarity and adequate testing of technology improves the instructor's ability to adjust to problems when they occur. Lastly, most students are eager to show their techno-savvy skill sets and are often willing to assist or identify more-efficient ways of using technology. 


\section{Summary and Future Considerations}

Numerous experiences contribute to student learning, including personal and educational experiences. One link between these learning experiences today is technology because it is ubiquitous in students' lives. Technology is no longer a new or unusual feature in education and should be incorporated throughout a student's educational experience. Therefore, it is important for teachers and professors to communicate and strategize about ways to gradually prepare students for the professional world. This may require additional technology instruction for teachers and professors, as well as facilitating ideas on how to use technology across the curriculum. To continue the pipeline from secondary education to postsecondary education to professionalism, teachers and professors must talk with nonprofits, state and federal agencies, and others to determine what technological skills are currently needed in natural resource professions. As we know, these needs constantly change and will require increased amounts of communication. By ensuring that technological tools are a regular part of evidence-based learning both inside and outside the classroom, we will produce graduates better prepared to meet the needs of rangeland managers today.

\section{Acknowledgments}

The authors thank the students who indirectly contributed to this manuscript through trial and error and feedback on our use of technology in teaching throughout the years. We also thank Ellie Steinberg and Jennifer Wallner at SimBiotic Software for editing and providing images, as well as anonymous reviewers for their comments. The authors do no endorse or advocate any particular software or technology, and those mentioned in this manuscript are provided only as examples.

\section{References}

1. Lopez-Perez, M. V., M. C. Perez-Lopez, And L. RodriguezArizA. 2011. Blended learning in higher education: students' perceptions and their relation to outcomes. Computers $\mathcal{E}$ Education 56:818-826.

2. Hmelo-Silver, C. E. 2003. Analyzing collaborative knowledge construction: multiple methods for integrated understanding. Computers Eं Education 41:397-420.

3. Dori, J. D., And J. Belcher. 2005. How does technology-enabled active learning affect undergraduate students' understanding of electromagnetism concepts? The Journal of the Learning Sciences 14:243-279.
4. Lu, J., S. P. Lajoie, and J. Wiseman. 2010. Scaffolding problem-based learning with CSCL tools. Computer-Supported Collaborative Learning 5:283-298.

5. Brewer, C. 2003. Computers in the classroom: how information technology can improve conservation education. Conservation Biology 17:657-660.

6. Kirk, D. J., And T. L. Johnson. 2009. The use of blogs as a knowledge management tool. Academic Exchange Quarterly 13:50-55.

7. Declan, B. 2006. Virtual globes: the Web-wide world. Nature 439:776-778.

8. Schultz, R. B., J. J. Kerski, and T. C. Petterson. 2008. The use of virtual globes as a spatial learning tool with suggestions for metadata standards. Journal of Geography 107:27-34.

9. Young, J. R. 2012. A tech-happy professor reboots after hearing his teaching advice isn't working. The Chronicle of Higher Education 58(24):18-19.

10. Zhu, E., And M. Kaplan. 2011. Technology and teaching. In: M. Svinicki and W. J. McKeachie [EDs.]. McKeachie's teaching tips: strategies, research, and theory for college and university teachers. Belmont, CA, USA: Wadsworth Cengage Learning. p. 235-266.

11. Kulik, C.-L. C., And J. A. Kulik. 1991. Effectiveness of computer-based instruction: an updated analysis. Computers in $\mathrm{Hu}-$ man Behavior 7:75-94.

12. Bayraktar, S. 2002. A meta-analysis of the effectiveness of computer-assisted instruction in science education. Journal of Research on Technology in Education 34:173-188.

13. Scheckler, R. K. 2003. Virtual labs: a substitute for traditional labs? International Journal of Developmental Biology 47:231-236.

Authors are Assistant Professor, Dept of Forest, Rangeland, and Fire Sciences, University of Idaho, Moscow, ID 83844, USA, beth@uidaho.edu (Newingham); Assistant Professor, Range Science Program, North Dakota State University, Fargo, ND 58108, USA (Ganguli); and Associate Professor and Geospatial Extension Specialist, Office of Arid Lands Studies, School of Natural Resources and the Environment, University of Arizona, Tucson, AZ 85721, USA (Orr). Newingham teaches Ecological Monitoring and Analysis and Wildland Restoration Ecology. Ganguli teaches Introduction to Range Management, Grazing Ecology, and Habitat Management. Orr collaborates with Cooperative Extension professionals to incorporate innovations in NASA Earth systems science and associated geospatial technologies into educational programming. 